\title{
Café Coronary Death is a Misleading Medical Term that had been put and Applied Wrongly by Haugen in 1963, Instead of Choking Death
}

\author{
Othman Alfleesy* \\ Department of Forensic Medicine and Pathology, Aden University, South Yemen
}

*Corresponding author: Othman Alfleesy, Department of Forensic Medicine and Pathology, Aden University, South Yemen.
Received Date: January 09, 2020

Published Date: January 14, 2020

\begin{abstract}
Café coronary death is a misleading medical term that had been put and applied erroneously by [1]. This label and misdiagnosis (café death) should not be used and must be deleted and dropped from references and textbooks of modern medicine. Because it puts the medical student and less experience physician in confusion. It is like a puzzle. Review of a number of articles regarding this issue.
\end{abstract}

\section{Introduction}

Café coronary death1 - according to Haugen term - is a condition in which a healthy person who begins a meal, suddenly collapse and dies without any further distress as a result of food obstruction of air passages (pharynx, larynx). The cause of death is reflex vagal inhibition of the heart. The bolus stimulates recurrent laryngeal nerve a branch of vagus nerve which in turn causes reflex inhibition of the heart and cardiac arrest. Choking (complete or partial) occlusion of pharynx, larynx, bronchi, by a food bolus, while eating food is causing death that has been known and studied. Also, there is a choking by a liquid (water) leading to death too, in some cases. The incidence of asphyxia caused by food impact in pharynx, larynx, tracheas has been reported since1970. Not only these cases, but asphyxial cases in general were known and documented in literature in the history of medicine since centuries ago.

\section{History}

Historically, Haugen was the first to report a death in restaurants in 1963.He had introduced the term (cafe' coronary) which refers to obstruction of the upper airway by a bolus of food while eating in restaurant. These cases have been witnessed and erroneously ascribed to a heart attack according to Haugen wrong estimation of the restaurant case.

\section{Definitions}

Before discussion, I preferred to remind you with a number of definitions as follows [2-6]:

\section{Asphyxia}

Conventionally the term asphyxia has been applied to conditions in which the supply of oxygen to the blood and tissues has been reduced or interrupted.

\section{Choking}

Choking is an occlusion or blockage of the upper airway by food or other objects, which prevents a person from breathing effectively which may lead to asphyxia and sudden death. It might occur by solid(food) or liquid(water)and could be complete occlusion or partial.

\section{Gagging}

Is a form of asphyxia caused by obstructing of breathing after insertion of object inside the mouth (obstructing pharynx and larynx). commonly used handkerchief or any soft material.

\section{Suffocation}

Is a form of asphyxia caused by mechanical obstruction to the passages of air into respiratory tract by means other than 
constriction of the neck (hanging, strangulation, throttling), and drowning. It includes:1-smothering (obstruction of air passages from outside).2-choking (obstruction of air passages from inside.3Traumatic asphyxia (obstruction to respiratory movements-as setting on the chest).

\section{Discussion}

It is noted that there are clear errors in the history of medicine, but some errors still repeated by all, despite the progress of medicine, practice and expertise.

There is no confusing similarity between symptoms of coronary trouble (angina pectoris, myocardial infarction) and obstruction of air passages (choking) to have difficulty for giving a correct diagnosis. It is impossible to speak about lung cancer and finally you say I mean colon cancer. How could this be accepted logically? It is unacceptable in science to justify the cause of death in this manner as Haugen suggested: choking due to coronary artery trouble. Haugen was unsuccessful in this term and concept (café coronary death). If he suggested in his differential diagnosis that this case resembles cardiac attack, this could be accepted scientifically. Here the question poses itself: Did Haugen perform the autopsy to this person? Remember that, the person may have heart attack while he is eating his meal.

It is mandatory to make differential diagnosis in medicine to have final diagnosis through comparison between symptoms similarities in different diseases and to exclude or rule out others. For example, to compare between renal colic pain in the right side of the abdomen and acute appendicitis, when a patient came to emergency having a pain in his right flank and you perform physical examination and investigation to get the final diagnosis.

I am confident that Haugen had not sufficient experience in the field of internal medicine, otherwise he could give a correct diagnosis or put a scientific and logic explanation. Haugen was looking to that person who died after eating his dinner in restaurant like an ordinary man not with the eyes and suspicious of specialized physician or forensic medicine specialist, because in such case the prompt and immediate help is needed, as a sudden death by this reason is fast. But after death everything is easy to be diagnosed in mortuary. There is no direct clear-cut similarity has been shown between the clinical picture of air passages obstruction (choking) and heart attack (Myocardial infarction) - in medical references.

\section{Symptom}

\section{In heart attack (myocardial Infraction)}

The cardinal symptoms of myocardial infarction are chest pain which may radiate to the arms, left shoulder, back, neck and/or jaw. The pain is often described as severe retrosternal chest pain pushing him to scream or shout [5]. Others described as squeezing or tightness like a band around the chest. Also, symptoms of myocardial ischemia can also include feeling of shortness of breath, vomiting, hypotension (blood pressure falls), pallor, sweating, tachycardia and others. Are these symptoms present in choking cases?

\section{In choking}

while in choking there is no severe pain(retrosternal pain) ,there is persistent cough(in partial), speechless, breathlessness(the person unable to speak and breath in complete), motionless, dyspnea, open eyes, cyanosis, loss of consciousness (collapse), and death occur in quick succession unless the object is dislodged. While in myocardial infarction the high percentage takes a time. Collapse can be caused by foreign bodies in larynx or trachea. I was surprised to find that some authors wrote vomiting of a choked person. If this occurs (vomiting) the problem would be solved soon. The expert physician in internal medicine will never get difficulty in determining the cause and diagnosis of the case. What confirms my saying is what I found during my review of a number of articles, that some researchers and doctors have written that in the cases of choking they request different investigations to make a correct diagnosis. As for example: ECG, CT scan echocardiography, chest X-ray, Complete blood tests.........etc. And to come next day for completing all investigation, how could this be done? and how this could be straightforward? Here is asphyxiated case how could you have a time to do different tests, while death might occur immediately or not more than 3 minutes in complete blockage. This in need for immediate and urgent interference. It is submitting to the rule (all or none). I think those who wrote such wrong information in their articles have never seen nor treated such cases. Here I want to narrate a story to a family of my relatives, their child was choking in his larynx (obstruction) with a coin ,The father was anxious hesitating to call others for help, etc. but the mother inserted her fingers violently to remove the coin and she succeeded, she removed it with stained blood, but to save the life of her son.

\section{Diagnosis}

The diagnosis of café coronary syndrome can only be made with confidence by an experienced physician easily after the clinical history and circumstances of death have been clearly established and a thorough physical examination, if there are no witness. Impacted material must be dislodged (removed) urgent for saving life otherwise you will demonstrate it in the airway passages at autopsy, unless extracted by those attempting resuscitation). Circumstance of death is an indicator for correct diagnosis.

\section{Conclusion}

Café coronary death is a medical term had been put and applied wrongly by Haugen in 1963 in order to denote choking another independent medical term. This term (café coronary death) has confused medical students and less experienced doctors, because it refers to another medical term (choking) that is already present with a known and definite meaning in our daily life. This term (café) must be deleted from the references and textbook in order to have a correct meaning and concept of this case, because coronary death means trouble to heart while choking means trouble to air passages. It is impossible to speak about lung cancer and finally you say I mean colon cancer. This was the fault of Haugen and the science with its advancement, accuracy and clarity must not carry this fault forever to future. 


\section{Acknowledgment}

None.

\section{Conflict of Interest}

No conflict of interest.

\section{References}

1. Haugen RK (1963) The cafe coronary; sudden deaths in restaurants. JAMA 186: 142-143.
2. Abualragi b (2019) Textbook of Forensic Medicine.

3. Parikhs (1990) Textbook of Medical Jurisprudence and Toxicology. ( $5^{\text {th }}$ edn).

4. CJ Polson (1985) The Essential of Forensic Medicine. ( $4^{\text {th }}$ edn).

5. Davidsons (1977) principles and practice of Medicine. (12 $\left.2^{\text {th }} \mathrm{edn}\right)$.

6. Pradeep Kumar MV (2008) Fast eating syndrome: a case report. Med Sci Law 48(1):78-81. 